\title{
Design and Analysis of 2-Axis Filament Winding Machine
}

\author{
Shiv Chaudhary \\ Mechanical Department, Sinhgad college of Engineering \\ DOI: 10.29322/IJSRP.11.10.2021.p11847 \\ http://dx.doi.org/10.29322/IJSRP.11.10.2021.p11847
}

\begin{abstract}
Filament winding is a process of loading a high degree of fibers to take advantage of high tensile in the manufacturing of hollow, generally cylindrical products. The process affords the high strength to weight ratio laminates and provides a high degree of control over uniformity and fiber orientation. Filament wound structures can be accurately machined, and the labor factor for filament winding is lower than other open moulding processes. The filament wound composite pipes are fabricated using high-strength fiber and resin matrix by hand lay-up using a 2-axis filament winding machine. In the present work, the lowcost filament winding machine is designed and developed for the fabrication of FRP pipes and cylindrical specimens.
\end{abstract}

Index Terms- Composite tube,2-axis Filament winding Machine, Composite Materials ,Glass fiber, Matrix.

\section{INTRODUCTION}

$\mathrm{F}$ ilament winding is an automated process for manufacturing advanced reinforced composite structural components. The machine creates the winding of resin-impregnated fibers around a mandrel and then hardening them so that the wound fiber can take the shape of the mandrel. Composite materials are receiving so much attention because of the demand for high-strength lightweight structures. Composites consist of multi-phase materials having at least one matrix and one dispersed phase. The matrix phase can be any bonding agent like glue, plastics, or metals, and the dispersed phase may be in the form of fibers, particles, or flakes.

A filament winding system essentially consists of three basic units;

1. A fibre spool holder and the equipment for controlling the roving tension

2. An impregnation system which includes the resin bath and equipment necessary to control the resin impregnating the roving, e.g resin temperature control, pressure roller, doctor blade etc.

3. A winding machine by which the mandrel is rotated and the pay-out-eye is traversed to lay the fibres uniformly over the surface.

A high degree of automation is required in all three units for accuracy and reproducibility, as well as to produce high-quality products. Using a central computer system, these machines can be controlled individually or in unison. Simple analogue feedback systems control the fibre tension and resin impregnation. The use of independent hard-wired controllers in fiber tension control and resin impregnation control reduces system connections. Because the winding machine is more sophisticated, it is controlled by a computer which can move the machine's axes along a predefined course.

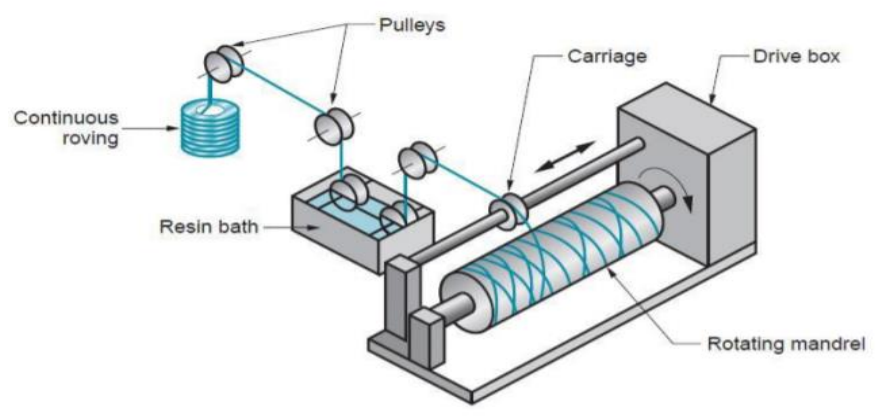

Figure 1: Filament Winding Machine

\section{LiterATURE REVIEW}

The following is a classification of the literature review conducted in the area of Filament Winding Machine in relation to the current work:

A well-designed FRP composite can absorb more energy than metals, according to several researchers; natural composite materials such as kenaf, silk, and hemp fibre reinforced composite tubes subjected to axial crushing will fracture to obtain energy absorption rather than the fibre deformation seen in metal tubing. As previously stated, delamination, local buckling, and bending failure modes contribute the most to energy absorption. In natural fiber-reinforced composite tubes, the effects of parameters such as fibre orientation on axial crushing behaviour were investigated experimentally.

According to Mertiny P and Ellyin F [1], machining FPRP causes damage such as delamination, fibre pull-out, fibre fragmentation, burring, and fuzzing.

Surface roughness in turning operations utilising Taguchi technique for cemented carbide tools was suggested by Abdalla [2] to increase the machinability of composites.

B. Sidda Reddy et al. [4] conducted research on polymer composite machining. They came to the conclusion that faster cutting speeds result in a better surface finish.

S. Rajesh [5] investigated multi-response surface machining parameter optimization. Pankaj Sharma [6] attempted a Taguchibased Grey Relational Analysis investigation of machining parameters in CNC turning. This method has resulted in lower cutting forces, less damage, and less tool wear as compared to traditional drilling. 
The Optimization of 6061T6 CNC Boring Process Using the Taguchi Method and Grey Relational Analysis was described by Show-ShyanLin et al. [7]. Using the Taguchi approach, optimise the cutting parameters for turning operations. Muhammad AL Firdausi bin johari [8]

In high-speed CNC turning of AISI P-20 tool steel, Anil Gupta [9] reported. Because of the non-homogeneous nature of the material, machining FPRP is problematic. For various work materials, several writers investigated the effect of process factors on tool wear. However, there are little research on tool wear in FPRP in the literature. The majority of studies have focused on the characterisation of natural fibre composites, although literature $[10,11]$ shows that mechanical property prediction is limited. Taguchi method and ANOVA approaches were used in few investigations on roselle fiber/particle reinforced polymer composites. [12]

Bartosz et al. [13] investigated the behaviour of axially crushed hemp yarns/epoxy composite tubes in an experimental study. The fibre orientation angles of $10,30,45,60$, and 90 degrees of planned winding orientations were investigated. The pin filament winding technique was used to prepare the tube samples. The reinforcements with the highest stress and modulus were found to be positioned at 10 degrees to the main axis.

\section{FILAMENT Winding MACHINE}

\section{A. Problem statement}

In today's industries, filament winding machines are particularly specific and important in application. For this, we now have very complex equipment that are controlled by computers and PLCs. The procedure is highly mechanised and therefore more expensive. The cost of filament winding machines with 5 to 7 axes ranges from Rs.2,40,00,000 to Rs.5,60,00,000. There is no information available on the pricing range of two-axis winding machines. According to a market assessment based on multiple price quotations, the smallest filament winding machines presently cost between Rs.28,00,000 and Rs.80,00,000, making them unaffordable for small-scale or research applications. Keeping cost reduction in mind, a small-scale winding machine was designed.

\section{B. Objective}

The main objective is to create a Computer-Aided Design and Finite Element Analysis of a low-cost 2-axis filament winding machine to produce small size cylindrical specimen of fiberreinforced plastics, as it is not available in the market, this can be achieved by the followings ways;

1. By eliminating the use of $\mathrm{CNC}$ which leads to the reduction of cost, as CNC software are quite costly.

2. By using materials that are less costly and easily available.

3. By reducing the axis of the machine to 2 axis which reduces the cost, but only cylindrical parts can be manufactured.

\section{Use of Simulation software}

The prime point of this research work is the implementation of CAD and CAM software. The work is based on the design and analysis of Filament Winding Machine, for that software's like Solidworks and ANSYS were used. For creating the design of the 2-axis machine's various parts drafting and assembly Solidworks is used and for static and modal analysis ANSYS is used.

\section{B. Methodology}

1. Design: Design of filament winding machine and parts like mandrel, carriage, frame and screw.

2. Calculations: deciding factor which influence production of composite material.

3. Modeling: Software modeling to visualize final assembly.

4. Analysis: Finite element analysis of the final design for calculating strength and behaviour of structure.

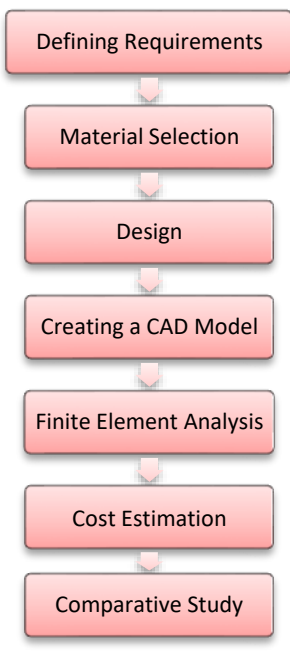

Figure 2 : Methodology steps

\section{DESIGN AND ANALYSIS}

\section{A. Mechanical Design.}

The following are the factors affecting the selection of gear ratio

1. Load moment of inertia

2. Desired maximum acceleration

3. Other factors like friction, fibre tension etc.

The major criterion for optimum motor performance is armature energy dissipation. This is determined by the velocity profile as well as the ratio of the load and rotor moments of inertia. As a result, the motor and gear ratio should be chosen so that the load moment of inertia equals the rotor moment of inertia for optimal output. This idea supports the mechanical design of the power transmission and advises using lightweight materials in the building of moving elements.

i. Frame Calculation:

Size of section: $25 \times 25 \mathrm{~mm}$

Thickness of section: $2 \mathrm{~mm}$

Total weight of acted is considered as: $15 \mathrm{~kg}$

$=15 \times 9.81 \mathrm{~N}$

$=147.15 \mathrm{~N}$

Weight on one hollow Square bar $=7.5 \mathrm{~kg}$

$=7.5 \times 9.81 \mathrm{~N}$

$=73.58 \mathrm{~N}$

$\mathrm{x}=\mathrm{y}=12.5 \mathrm{~mm}$ 
Area of cross-section is $=174 \mathrm{~mm}^{\wedge} 2$

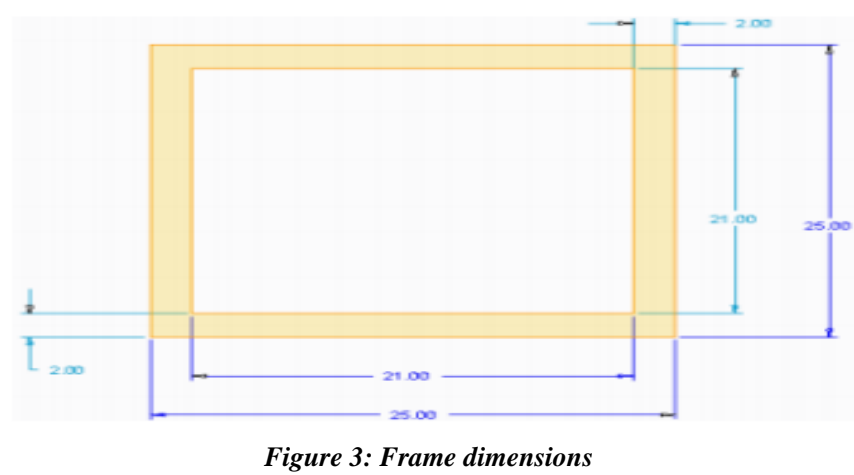

As the load is distributed on the pipe which is subjected to the load as simply supported beam with uniformly distributed load the bending moment on the pipe is calculated as,

$\mathrm{M} / \mathrm{I}=\mathrm{b} / \mathrm{Y}$

$\mathrm{I}=\mathrm{BH} 3 / 12-\mathrm{bh} 3 / 12$

$\mathrm{I}=32552-16206$

$=16346 \mathrm{~mm} 4$

$\mathrm{Mb}=\mathrm{WL} 2 / 8$

$=147.15 \times 1 / 8=18.3937 \mathrm{~N}-\mathrm{m}$

$\mathrm{Mb}=18393 \mathrm{~N}-\mathrm{mm}$

$18393 / 16346=\mathrm{b} / 12.5$

$\mathrm{b}=14.06 \mathrm{~N} / \mathrm{mm}$

ii. Shaft Calculation:

We select M.S material for shaft,

$\mathrm{Q}=7860 \mathrm{~kg} / \mathrm{m} 3$

$\mathrm{L}=0.765 \mathrm{~m}$

$\mathrm{Mt}=$ torsional moment

Maximum bending stress $=\left(\mathrm{M}^{*} \mathrm{r}\right) / \mathrm{I}$

$\mathrm{M}=\mathrm{WL} 2 / 8=14071 \mathrm{~N} \mathrm{~mm}$

$\mathrm{I}=\pi \mathrm{r} 4 / 4=\pi \mathrm{X} \mathrm{r} 4 \mathrm{X} 0.25=0.785 \mathrm{X} \mathrm{r} 4$

Allowable bending stress of Mild steel is $155 \mathrm{~N} / \mathrm{mm} 2$

$155=(14071 * \mathrm{r}) / 0.785 \mathrm{r} 4=10.75 \mathrm{~mm}$

So $\mathrm{r}=10.75 \mathrm{~mm}$ but we are taking the diameter of shaft as 20

$\mathrm{mm}$ by considering the factor of safety as 2 .

iii. Motor Selection and Calculation:

Consider weight of the consumable $=1 \mathrm{~kg}$ (approximately)

So, the force applied is equal to $=1 \times 9.81$ newton.

$\mathrm{F}=9.81 \mathrm{~N}$

Hence, the torque required $=9.81 \times 0.05$

$=0.4905 \mathrm{Nm}$

So, we have to select a motor having considerably similar torque as calculated.

Voltage $=12 \mathrm{~V}$, Current $=2 \mathrm{Amp}$, Speed $=30 \mathrm{RPM}$

We know that, $\mathrm{P}=\mathrm{V} * \mathrm{I}$

$=12 * 2=24 \mathrm{~W}$

$\mathrm{P}=2 * \pi * \mathrm{~N} * \mathrm{~T} / 60$

$\mathrm{T}=7.64 \mathrm{Nm}$

\section{B. CAD Design's.}

1) Machine Frame.
The machine's frame is composed of a hollow mild steel framework to reduce the overall weight to a minimum. The machine's frame supports the mandrel as well as other components such as motors, carriage-rail support beams, carriages, and cross-members. This frame is made of mild steel to achieve great stiffness and strength while being lightweight.

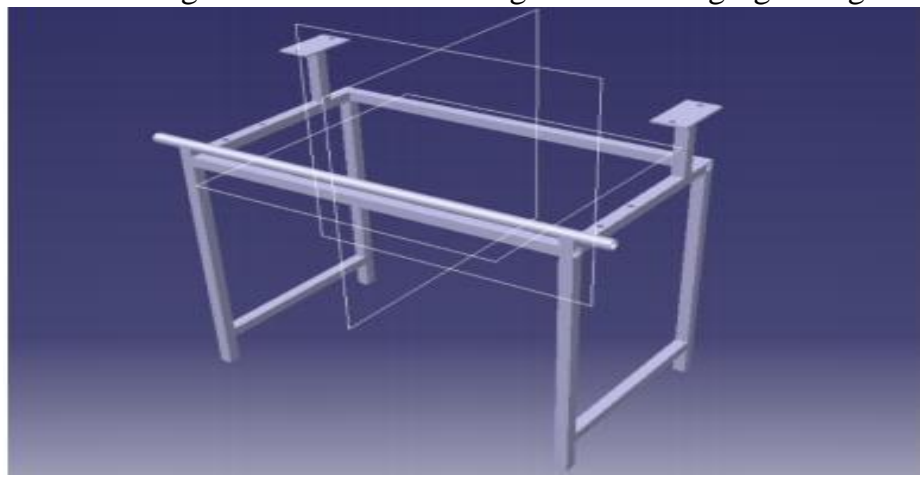

Figure 4: Frame Design

2) Mandrel.

The machine is made for mandrels up to one meter in length. These mandrels can be manufactured to a certain length. As a result, the gap between the two centers is maintained. The mandrel can be removed and replaced on the standard-length bar for shorter or longer pieces. The filament wraps around the mandrel, which is a revolving cylinder. It supports the developing composite cylinder and is attached to the frame by bearings and a shaft controlled by a stepper motor via a belt system. The mandrel is made to make a composite "cylinder with a 9-centimeter inner diameter (ID) and lengths up to 60 centimeters.

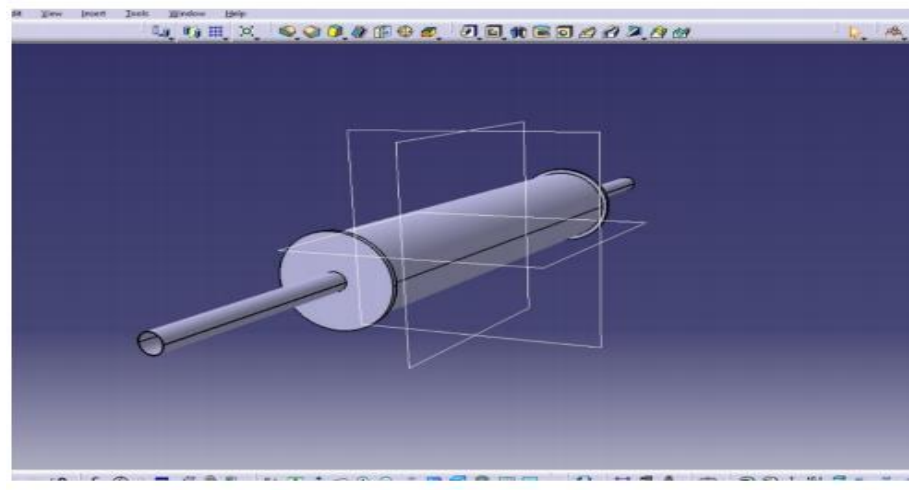

Figure 5: Mandrel Design

\section{3) Carriage.}

The carriage is the most significant portion of the filament winding machine in terms of mechanical design. The cantilever deflection and bearing clearances at all bearing contact sites must be minimised to lessen the Y-axis' pitching flexibility. The system must offer angular support for the cross-member while allowing it to extend with the least amount of friction possible. This part is made using M.S. Sheet section as the raw material to minimise stress concentration effects and for accuracy reasons. 


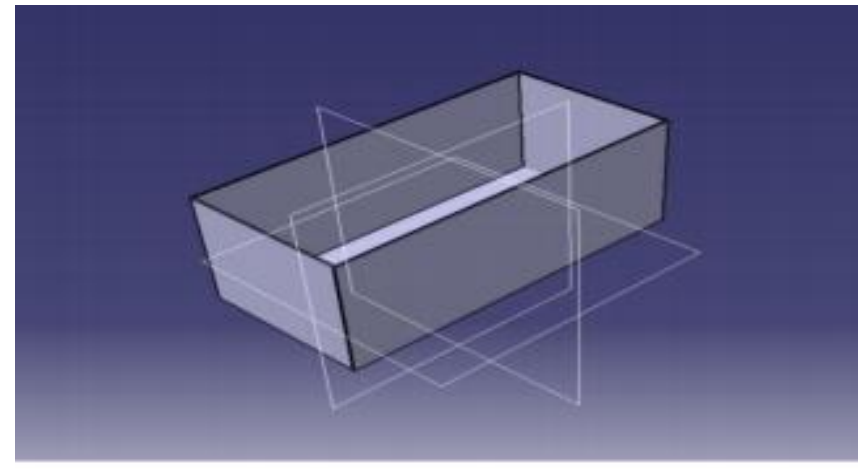

Figure 6: Carriage Design

4) Lead Screw.

A lengthy worm screw is attached to the horizontal slide, which is operated by a 30rpm DC motor. Over the lengthy lead screw, two nuts are used. The screw has a $15 \mathrm{~mm}$ diameter and a $4.9 \mathrm{~mm}$ outer diameter bush. The carriage is coupled to a lead screw with two nuts positioned over it, and movement of the screw drives the carriage back and forth.

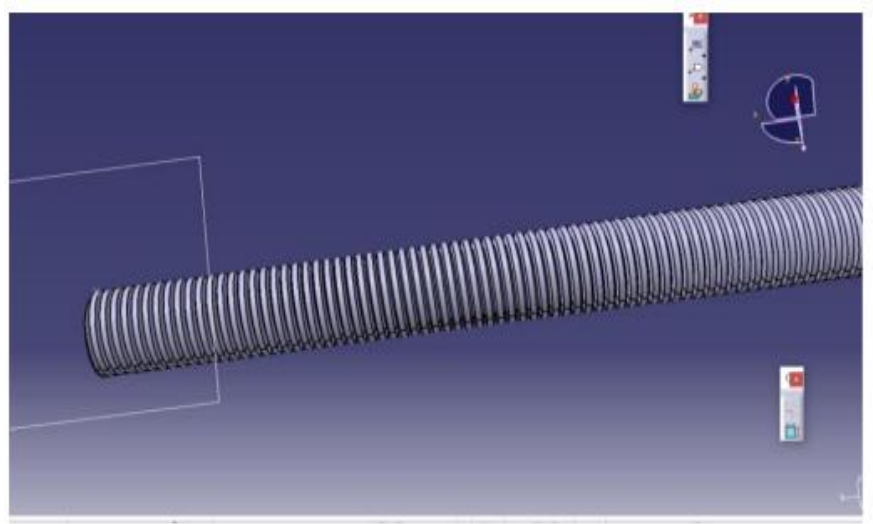

Figure 7: Lead Screw Design

C. Assembly and Drafting.

1) Assembly.

All the parts that are designed and are combined together to visualize the final model.

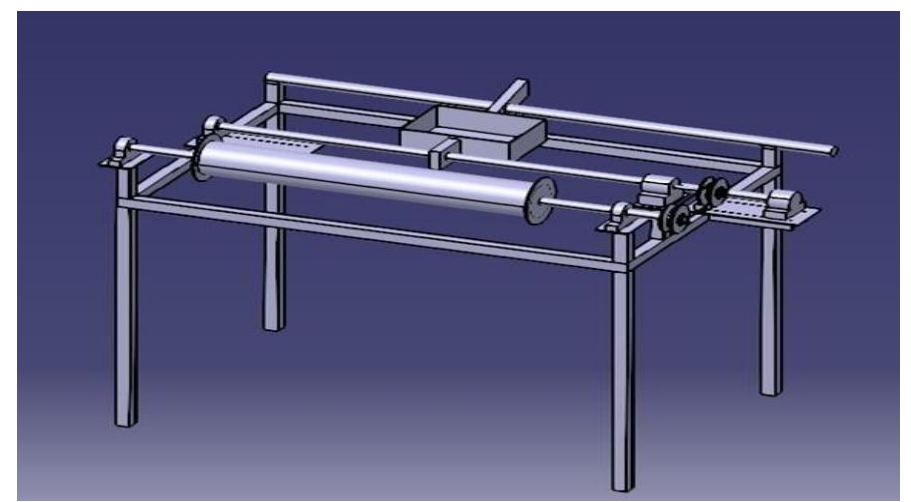

Figure 8: Assembly
2) Drafting.
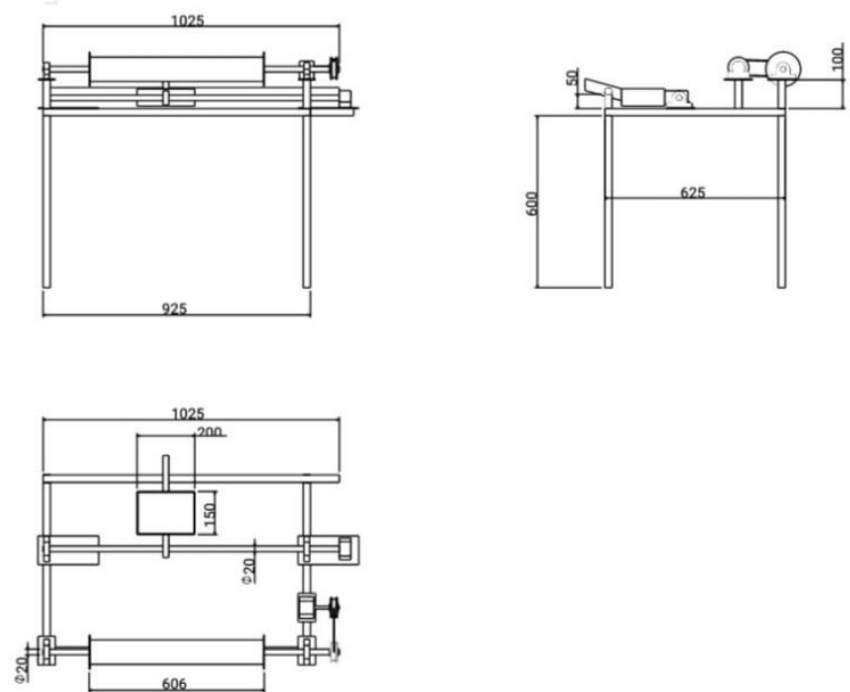

Figure 9 : Drafting diagrams

D. Filament Winding Machine Analysis.

1) Modal Analysis.

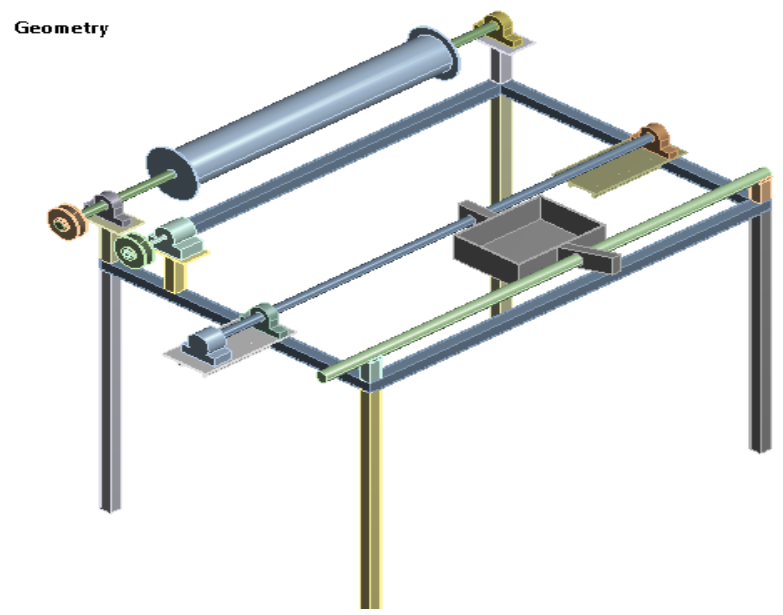

Figure 10: Geometry

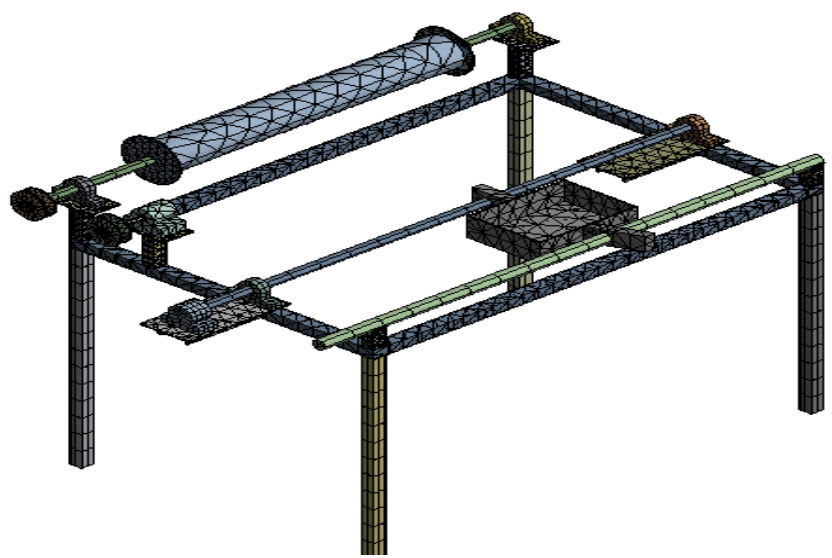

Figure 11: Meshing 
- NODES AND ELEMENTS:

\begin{tabular}{|l|l|}
\multicolumn{3}{|c|}{ Table 1: Nodes and Elements } \\
\hline Statistics \\
\begin{tabular}{|l|l|}
\hline Nodes & 31494 \\
\hline$\square$ Elements & 12511 \\
\hline
\end{tabular}
\end{tabular}

- Boundary Conditions:

The chassis is fixed from bottom.

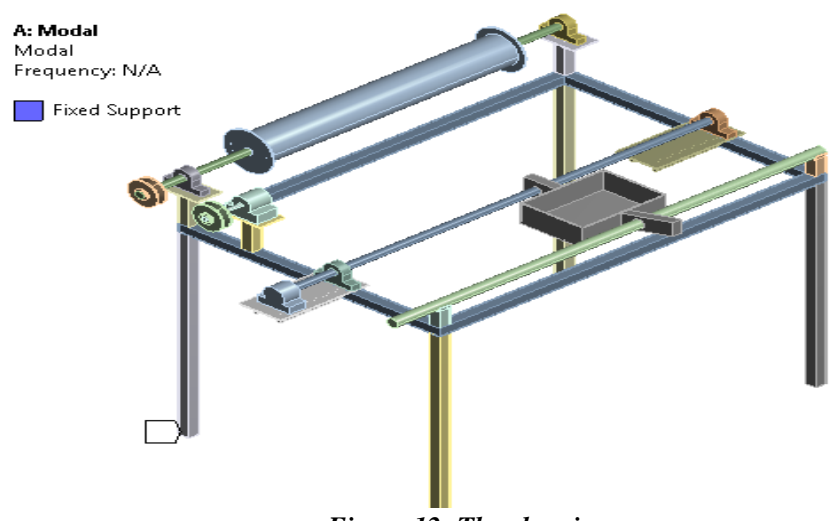

Figure 12: The chassis

2) Modal Analysis Result And Plots.

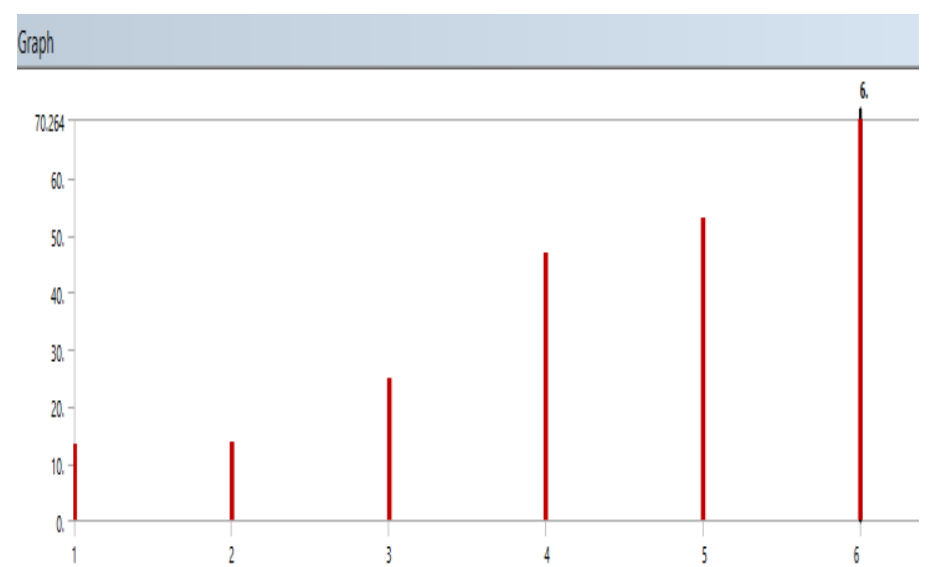

Figure 13 : Modal analysis result plot

Table 2: Mode and Frequency Data

Tabular Data
\begin{tabular}{|l|l|l|l|}
\hline & Mode & Frequency [Hz] \\
\hline 1 & 1. & 13.251 \\
\hline 2 & 2. & 13.66 \\
\hline 3 & 3. & 24.861 \\
\hline 4 & 4. & 46.765 \\
\hline 5. & 5. & 53.087 \\
\hline 6 & 6. & 70.264 \\
\hline
\end{tabular}

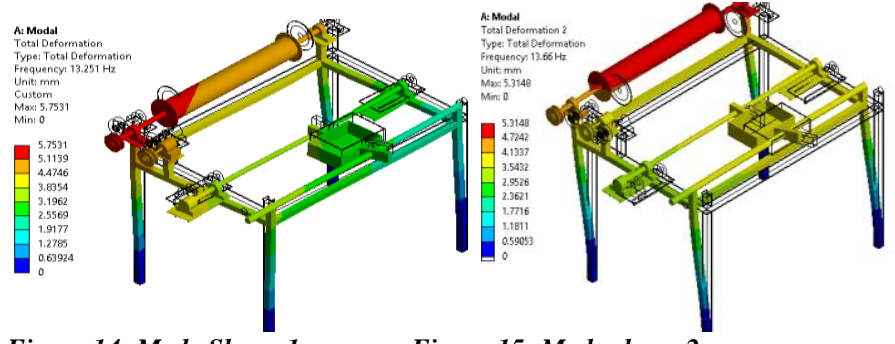

Figure 14: Mode Shape 1

Figure 15: Mode shape 2
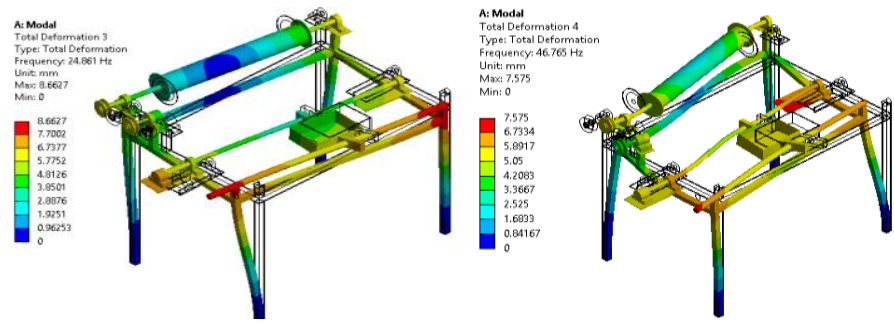

Figure 16:Mode Shape 3

Figure 17: Mode Shape 4

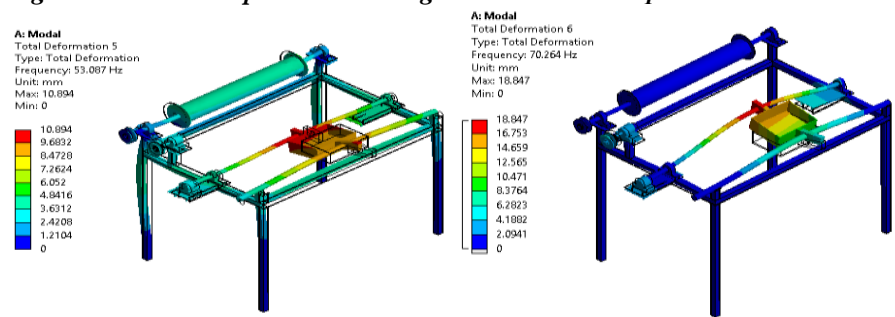

Figure 18: Mode Shape 5

Figure 19: Mode Shape 6

3) Static Analysis.

- Boundary Condition:

If the weight of the filament is considered to be $5 \mathrm{~kg}$ and the gravitational forces are applied on the structure.

B: Static Structural

Static Structural

Time: $1 . s$

A Fixed Support

B Force: $50 . \mathrm{N}$

C Force 2: $50 . \mathrm{N}$

D Standard Earth Gravity: $9806.6 \mathrm{~mm} / \mathrm{s}^{2}$

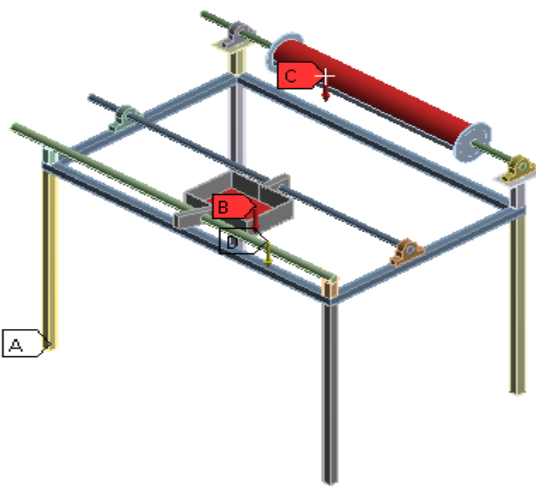

Figure 20 : Static Structure

Total Deformation Plot:

B: Static Structural
Total Deformation
Type: Total Deformation
Unit: $m$ mm
Time: 1
Custom
Max: 2.0679
Min: 0
\[ \begin{array}{l}2.0679 \\ 1.8382 \\ 1.6084 \\ 1.3786 \\ 1.1488 \\ 0.91908 \\ 0.68931 \\ 0.45954 \\ 0.22977 \\ 0\end{array} \]

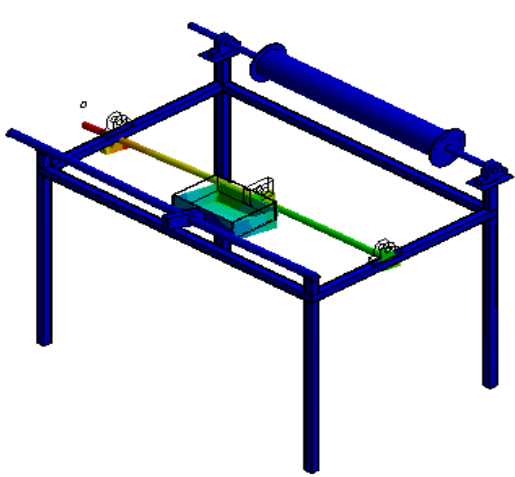

Figure 21 : Total deformation plot 
- Equivalent stress plot:

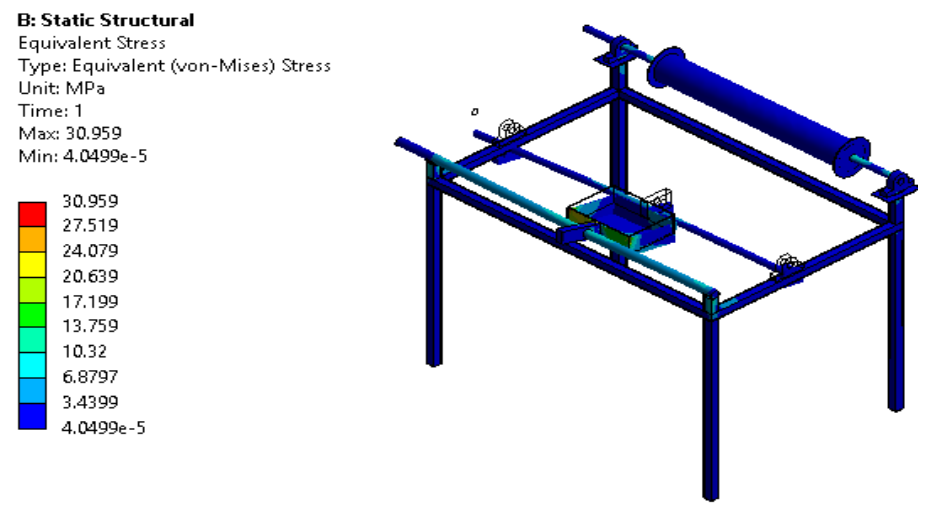

Figure 22: Equivalent stress plot

- Maximum Principal Stress:

B: Static Structural
Maximum Principal Stress
Type: Maximum Principal Stress
Unit: MPa
Time: 1
Custom
Max: 30.501
Min: -6.6141
\begin{tabular}{|l}
30.501 \\
26.377 \\
22.253 \\
18.129 \\
14.005 \\
9.8813 \\
5.7575 \\
1.6336 \\
-2.4903 \\
-6.6141
\end{tabular}

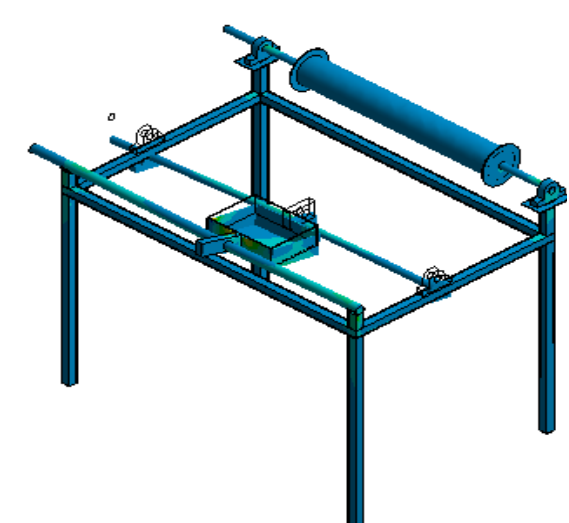

Figure 23: Maximum Principal Stress

\section{4) Result of Analysis.}

In this following analysis we have done modal analysis and static analysis on the frame of a filament winding machine to plot the fundamental frequency range of the chassis in the following analysis. The fundamental frequency of a product is the natural frequency range within which it remains undamaged, and if the practical frequency of the chassis exceeds the plotted frequency, the chassis will display deviation or deformation. The presented total deformation, equivalent stress, and maximum principal stress plots in static analysis, proving that the machine can withstand them without failure.

\section{RESULT AND CONCLUSION}

\section{1) Result.}

A low-cost 2-axis filament winding machine was designed at minimal cost to produce small scale specimen.

The following is the production cost:

i. Bearings 6204 Rs.300per unit. Quantity=4 Price

$=$ Rs. $1,200 /-$

ii. M.S. Pipes Square c/s $25 * 25 \mathrm{~mm}$ Rs. $40 / \mathrm{Kg}$.

Quantity $=22.5 \mathrm{Kg}$ Price $=$ Rs.900/-

iii. $\quad$ Lead screw $=$ Rs.450/-

iv. $\quad$ D.C. Motor $=$ Rs. $150 /-$

v. Mandrel Pipe $=$ Rs.120/-

vi. M.S. Hollow circular shaft, 2no. Rs.150/unit = Rs.300/- vii. Fabrication charges $=$ Rs.2,000/-

As a result, the overall cost of manufacture, including parts and fabrication, is Rs.5,620/-.

\section{2) Conclusion.}

The machine can be successfully used to fabricate small sized specimens with any fiber and resin combination. Using mandrels of various sizes, the machine can produce cylindrical parts of various diameters. To decrease the load on the motor that rotates the mandrel, the weight of the mandrel could be lowered.

However, the length of the specimen that may be generated is limited to $60 \mathrm{~mm}$ by the machine that was designed. Pitch length, helix angle, and pipe length are all controllable factors on the machine.

\section{REFERENCES}

[1] .Mertiny P and Ellyin F (2002), "Influence of the filament winding tension on physical and mechanical properties of reinforced composites' Composites Part.

[2] Abdalla, F.H.; Mutasher, S.A.; Khalid, Y.A.; Sapuan, S.M.; Hamouda, A.M.S.; Sahari, B.B.; and Hamdan, M.M., (2007). Design and fabrication oflow cost filament winding machine. Materials and Design, 28(1), 234-239.

[3] Johansen B.S.; Lystrup A.; and Jensen, M.T. (1998). CADPATH: Acomplete program for the CAD-, CAE- and CAM-winding of advanced fibercomposites. Journal of Materials Processing Technology, 77(1-3), 194200.

[4] Composite filament wound, CK composite, Inc. (2012), Available:http://www.ckcomposites.com/files/documents/CK_BROCHUR E_NP.PDF.

[5] . Bolt 3 application note, Advanced Mechanical Technology Inc. (2008).Available: http://amti.biz/PDFDownloads/Bolt3applnote.pdf.

[6] Motion control application notes (2008). Baldor Electric Company. Available: http://www.baldor.com/pdf/manuals/1200-299.pdf.

[7] 7. Power transmission and sizing (2012). Available: http://v5.books.elsevier.com/bookscat/samples/9780750667401

[8] Mohan R, Kishore, Shridar M K and Rao R M V G K (1983) 'compressive strength of jute/glass hybrid fiber composite', Journal of material science letters, vol. 2 ,- pp 99- 102

[9] Rengarajan and Kishore (1985), 'Jute/glass sandwich composite, Journal of reinforced plastics and composites, Vol. 4, pp 186-19'4.

[10] Rajendran, I and Vijayarangan, S., A Parametric Study of Free Vibration of Leaf Springs, Proc .of 14th IntI. Conf. on CADI CAM, Robotics \& Factories of the Future, Coimbatore, India .1-3rd Dec 1993, p 77-85

[11] Lye S.W and Boey F.Y.C (1995), 'Development of a low-cost prototype filament- winding system for composite. components, Journal of Materials Processing Technology, Vol. 52, Issues 2-4, pp.570-584

[12] Abdalla F.H, Mutasher S.A, Khalid Y.A, Sapuan S.M, Hamouda H.M.S, Sahari B.B and Hamdan M.M Design and Fabrication of Low Cost filament Winding Machine, Materials and Design, Vol. 28, 2007, pp.234-239 .

[13] Hernandez-Moreno H, Douchin B, Collombet F, Choqueuse D. and Davies $\mathrm{P}$, (2008), "Influence of winding pattern on the mechanical behavior of filament wound composite cylinders under external' pressure" Composites Science and Technology, Volume 68, Issues 3-4, pp. 101,5-1024.

\section{AUTHORS}

First Author - Shiv Chaudhary, Bachelors of Mechanical Engineering, Sinhgad College of Engineering, shivchaudhary22.sc@gmail.com. 
International Journal of Scientific and Research Publications, Volume 11, Issue 10, October 2021

This publication is licensed under Creative Commons Attribution CC BY. 